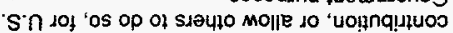

s!4t to ullot pausılnd aul exnposdas

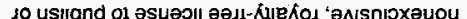

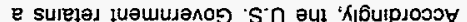

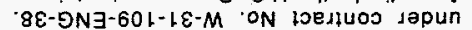

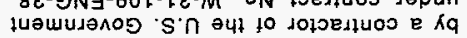

pedounne uөəq seu jd!josne

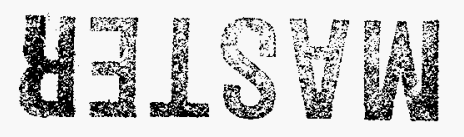

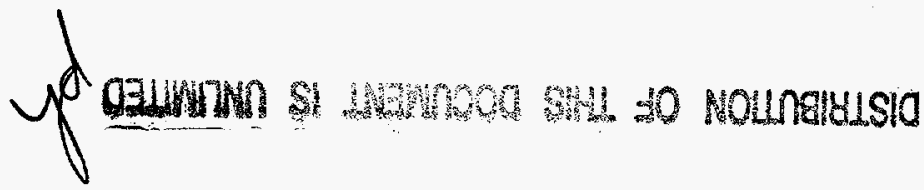

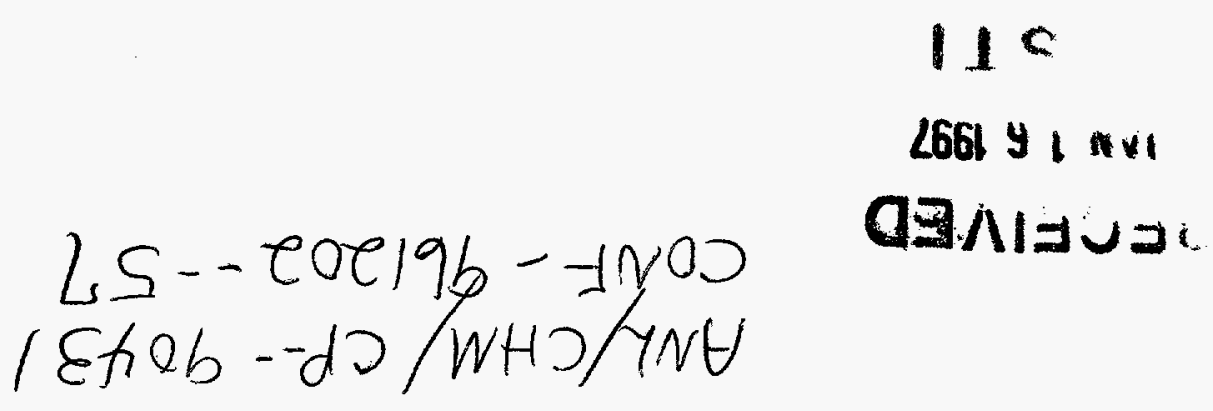

$6 \varepsilon t 09$

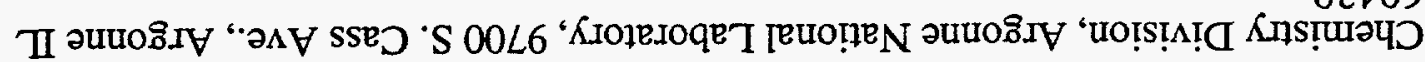
WTOHEבCOS ${ }^{\circ} \mathrm{I}$

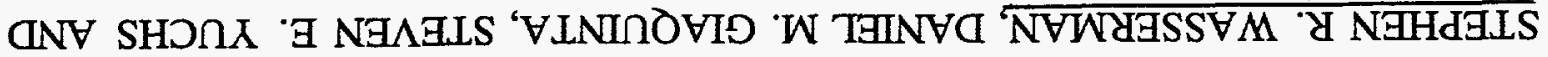

SALVDITISONIWATV OLNI GGIVTVD\&GINI SNOI TVIGW

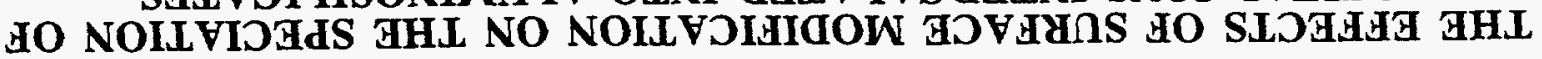

VW' 'uolsog

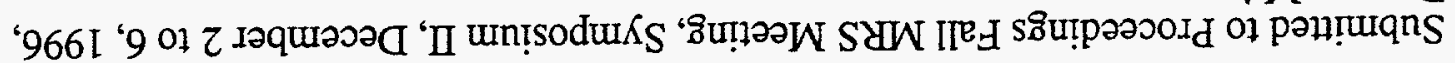




\section{DISCLAIMER}

This report was prepared as an account of work sponsored by an agency of the United States Government. Neither the United States Government nor any agency thereof, nor any of their employees, make any warranty, express or implied, or assumes any legal liability or responsibility for the accuracy, completeness, or usefulness of any information, apparatus, product, or process disclosed, or represents that its use would not infringe privately owned rights. Reference herein to any specific commercial product, process, or service by trade name, trademark, manufacturer, or otherwise does not necessarily constitute or imply its endorsement, recommendation, or favoring by the United States Government or any agency thereof. The views and opinions of authors expressed herein do not necessarily state or reflect those of the United States Government or any agency thereof. 


\section{DISCLAIMER}

Portions of this document may be illegible in electronic image products. Images are produced from the best available original document. 


\title{
THE EFFECTS OF SURFACE MODIFICATION ON THE SPECIATION OF METAL IONS INTERCALATED INTO ALUMINOSILICATES
}

STEPHEN R. WASSERMAN, DANIEL M. GIAQUINTA, STEVEN E. YUCHS AND L. SODERHOLM

Chemistry Division, Argonne National Laboratory, 9700 S. Cass Ave., Argonne II 60439.

\begin{abstract}
The effect of the addition of an organic monolayer to the surface of a clay mineral on the speciation of metal ions intercalated into the clay interlayer is probed by X-ray absorption spectroscopy. The presence of the monolayer changes the surface of the clay from hydrophilic to hydrophobic. It inhibits the interlayer ions from exchanging freely into environmental water and reduces the leach rate of cations out of the clay by approximately a factor of 20 . Significant changes are observed when these coated samples are treated under hydrothermal and thermal conditions. Reductions of uranium (VI), in the form of uranyl, and cupric ions occur. In addition, the uranium aggregates, forming small particles that appear similar to $\mathrm{UO}_{2}$. Comparable conglomeration occurs with lead cations and with the reduced copper species.
\end{abstract}

\section{INTRODUCTION}

Microporous aluminosilicates, including clay minerals and zeolites, are ion-exchange materials. 1,2 In their most common forms, they have the ability to incorporate cationic species within their matrices. Because of this property, microporous aluminosilicates have been proposed as storage media for hazardous waste. In this paper we use X-ray absorption spectroscopy (XAS) to examine the structure of cations held within smectite clay minerals and to determine how modification of the surface of the clay using an organic monolayer affects the coordination of the stored cation. The effects of hydrothermal and thermal processing on the coordination of the ions contained within these systems are also investigated.

Smectite clays consist of aluminosilicate sheets which contain a central section of octahedrally coordinated $\mathrm{Al}^{3+}$ that is sandwiched between two layers of tetrahedrally coordinated $\mathrm{Si}^{4+} .3$ Random substitutions, generally of $\mathrm{Mg}^{2+}$ for $\mathrm{Al}^{3+}$ and $\mathrm{Al}^{3+}$ for $\mathrm{Si}^{4+}$, result in a net negative charge in the lattice. This charge is balanced by cations in the interlayer between the sheets. The interlayer also contains water, some of which is complexed to the cations. The interlayer cations can be replaced by ion-exchange techniques with other positively charged species. ${ }^{4}$ For this study we have replaced the cations originally present in a clay, usually sodium, calcium, and potassium, with cationic metal species, including copper(II), nickel(II), lead(II), and uranyl $\left(\mathrm{UO}_{2}{ }^{2+}\right)$. The clay used for these experiments is bentonite, a form of montmorillonite.

Clays are naturally hydrophilic. This affinity for water, however, also facilitates the leaching of any hazardous species stored within the mineral. In order to isolate the cationic species within the clay interlayer, we have modified the surfaces of ion-exchanged smectite 
clays using alkylsilanes of the form $\mathrm{RSiX}_{3}, \mathrm{R}=\mathrm{C}_{2} \mathrm{H}_{5^{-}}, \mathrm{C}_{18} \mathrm{H}_{37-}, \mathrm{X}=-\mathrm{Cl},-\mathrm{OCH}_{3}$. This process is illustrated schematically in Figure 1 . The organosilanes bind covalently to the surface of the clay mineral and render the mineral hydrophobic. The presence of this coating inhibits the exchange of external water, and accompanying cations, into and out of the interlayer. 5

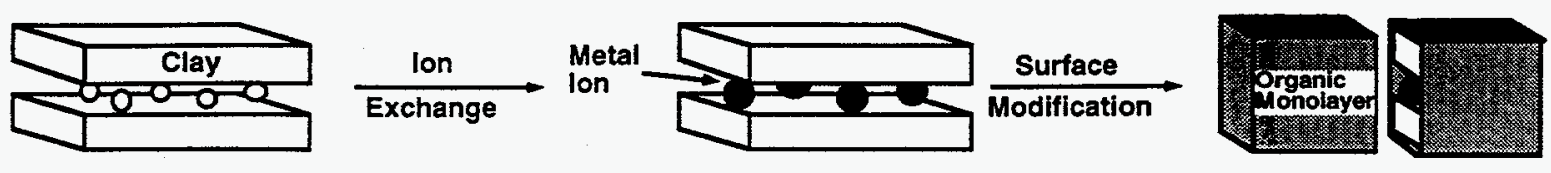

Figure 1. Schematic representation of ion exchange and organic encapsulation of ions within a smectite clay mineral.

\section{EXPERIMENT}

The general preparation of ion-exchanged clays has been described elsewhere. The $\mathrm{Ca}^{2+}$ form of bentonite was used as received (bentolite L, Southern Clay Products, Gonzales, Texas). The surfaces of the ion-exchanged clays were coated with octadecyltrimethoxysilane, $\mathrm{CH}_{3}\left(\mathrm{CH}_{2}\right)_{17} \mathrm{Si}\left(\mathrm{OCH}_{3}\right)_{3}$ (OTMS, Aldrich), and octadecyltrichlorosilane, $\mathrm{CH}_{3}\left(\mathrm{CH}_{2}\right)_{17} \mathrm{Si}\left(\mathrm{OCH}_{3}\right)_{3}$ (OTCS, Aldrich). The silanes were distilled and stored under dry nitrogen prior to use. The clay $(1 \mathrm{~g})$ and silane $(1 \mathrm{~mL})$ were added to anhydrous hexane (40 $\mathrm{mL}$ ). The mixture was stirred for $24 \mathrm{~h}$ at room temperature under a dry nitrogen atmosphere. A catalyst, 3-indolepropionic acid $(0.01 \mathrm{~g})$, was added for the reaction of the trimethoxysilane with the clay surface. The samples were collected by centrifugation, washed three times with anhydrous hexane $(25 \mathrm{~mL})$ to remove any unreacted silane, and dried at room temperature. The process for the formation of the surface coatings is based on previous work on selfassembled monolayers. 6,7

The susceptibility of the encapsulated ions to leaching was evaluated by sonicating the clay sample $(0.5 \mathrm{~g})$ in a buffered solution of sodium acetate for $2 \mathrm{~h}$. This solution was prepared by adding glacial acetic acid $(5.7 \mathrm{~mL})$ and aqueous sodium hydroxide $(64.3 \mathrm{~mL}$ of a $1 \mathrm{~N}$ solution) to water $(1 \mathrm{~L})$. This fluid is the standard extraction fluid for the EPA toxicity characteristic leaching protocol (TCLP). The amounts of extracted ions were determined by ICP-MS.

Hydrothermal processing of the clay samples was performed in a sealed stainless steel Parr high pressure bomb (4746) with a Teflon ${ }^{\circledR}$ insert that contained clay (250 $\left.\mathrm{mg}\right)$ and deionized water $(10 \mathrm{~mL})$. The bomb was placed in a Lindberg crucible furnace and heated at $1^{\circ}$ per minute to $200^{\circ} \mathrm{C}$. The bomb was maintained at $200{ }^{\circ} \mathrm{C}$ and $15.8 \mathrm{~kg} / \mathrm{cm}^{2}$ (calc) for 20 hours, after which the samples were cooled radiatively to room temperature.

Thermal processing under nitrogen and hydrogen was performed in a specially designed catalyst cell for in situ X-ray absorption spectroscopy. The ion-exchanged clay (100 $\mathrm{mg}$ ) was placed in the sample holder of the cell. The remainder of the volume of the holder 
was filled with boron nitride to minimize movement of the clay sample. Kapton tape was used as the windows of the cell. The flow rate of nitrogen or hydrogen gas through the cell was approximately $5 \mathrm{~mL}$ per minute through a cell volume of $1 \mathrm{~cm}^{3}$. For rehydration of the clay after thermal processing, nitrogen was sparged through water prior to entering the sample holder.

X-ray absorption spectra were obtained at the National Synchrotron Light Source (NSLS) on beamlines X23A2 and X10C, and at the Stanford Synchrotron Radiation Laboratory (SSRL) on station 4-3. The beamlines were equipped with either a $<220>$ (SSRL and X10C) or $<311>(\mathrm{X} 23 \mathrm{~A} 2)$ double-crystal Si monochromator. Harmonics were rejected on $\mathrm{X} 10 \mathrm{C}$ by use of a mirror and at SSRL by detuning the monochromator to approximately $50 \%$ of the maximum X-ray intensity . Fluorescence spectra were collected using a Lytle detector that was purged with Ar gas. An appropriate 3 absorption lengths filter was placed between the sample and the ionization chamber of the detector. Calibration of the edges was maintained through simultaneous acquisition of the transmission spectrum of a reference material. The position of $k=0 \AA^{-1}$ was defined as the maximum in the derivative spectrum from the reference. Analysis of the EXAFS data was performed using theoretical phase shifts and scattering amplitudes from FEFF 3.25.8

\section{RESULTS AND DISCUSSION}
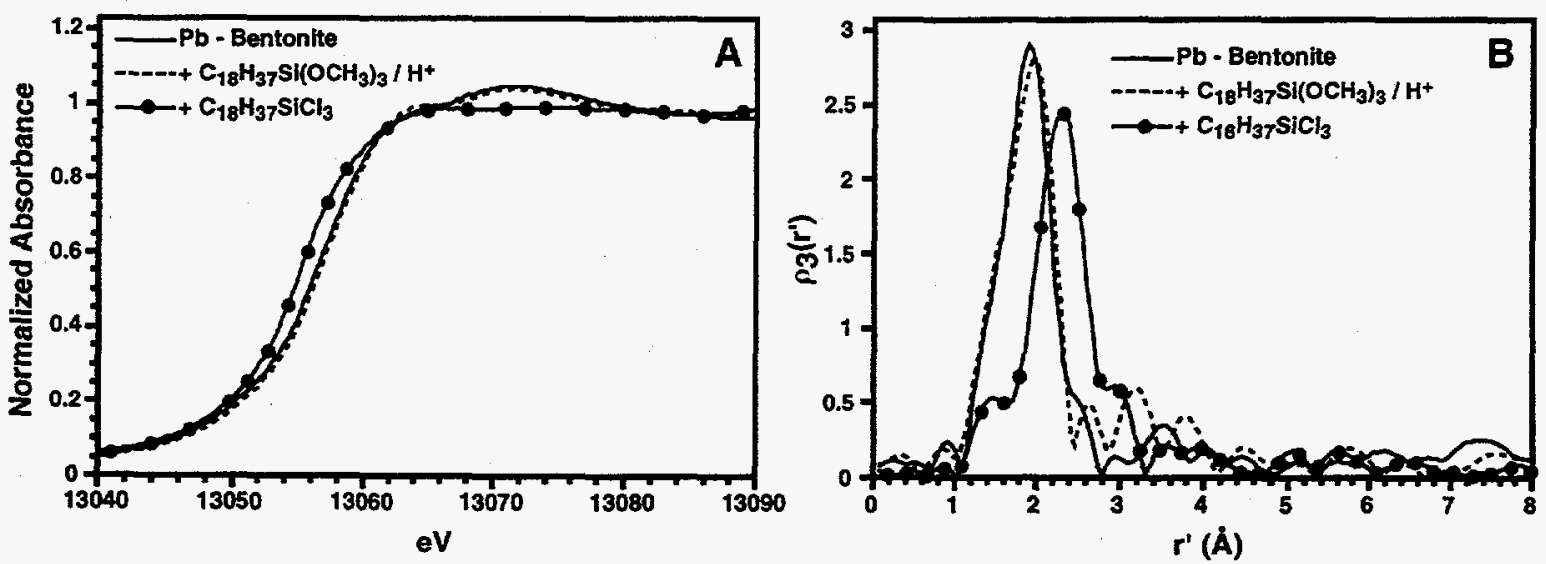

Figure 2. (A) X-ray absorption near edge spectra (XANES) and (B) radial structure functions (not phase corrected) for lead(II) in the interlayer of bentonite:

(1) ion-exchanged clay ( - ), (2) after formation of a monolayer from octadecyltrimethoxysilane $\left(\mathrm{C}_{18} \mathrm{H}_{37} \mathrm{Si}\left(\mathrm{OCH}_{3}\right)_{3},-\cdots\right)$, and (3) after formation of a monolayer from octadecyltrichlorosilane $\left(\mathrm{CH}_{3}\left(\mathrm{CH}_{2}\right)_{17} \mathrm{SiCl}_{3}\right.$, ¿-1. ). The range for the forward Fourier transforms was $\Delta \mathrm{k}=1.7-10.0$

Ion Coordination. Surface modification of ion-exchanged clays can lead to changes in the local coordination of the ions located within the interlayer. Figure 2 shows the near edge spectra (XANES) and radial structure functions for lead(II) ions in the interlayers of 
bentonite ( $\mathrm{Pb}$-bentonite) before and after addition of organic monolayers formed from octadecyltrichlorosilane (OTCS) and octadecyltrimethoxysilane (OTMS). The clays that result from addition of these two coatings are hydrophobic. The EXAFS data indicate that, in the original ion-exchanged clay, the coordinating species for the lead ions are oxygen atoms, presumably from water molecules contained within the interlayer of the clay. The XANES and radial distributions after addition of OTMS are similar to those of the original $\mathrm{Pb}$-bentonite. In contrast, when OTCS is used to form the monolayer, the XANES spectrum shifts to lower energy. The bond distance to the atoms in the first coordination sphere in the radial structure function increases by approximately $0.3 \AA$. The changes in the XANES and EXAFS spectra are consistent with the replacement of the water molecules originally complexed to the $\mathrm{Pb}(\mathrm{II})$ ion by chloride anions which are a byproduct from the reaction of the trichlorosilane. Similar results are observed when uranyl or copper(II) ions are placed within bentonite.

Table 1. Leachability in $\mathrm{mg}$ per $\mathrm{g}$ of clay of divalent cations from bentonite before and after surface modification. ${ }^{\mathrm{a}}$

\begin{tabular}{l|l|l|l} 
Cation & Ex -bentonite & $+\mathrm{C}_{18} \mathrm{H}_{37} \mathrm{Si}\left(\mathrm{OCH}_{3}\right)_{3}$ & $+\mathrm{C}_{18} \mathrm{H}_{37} \mathrm{SiCl}_{3}$ \\
\hline $\mathrm{Ni}^{2+}$ & 5.4 & 0.25 & \\
$\mathrm{Cu}^{2+}$ & 8.4 & 0.24 & \\
$\mathrm{~Pb}^{2+}$ & 33 & 1.9 & \\
$\mathrm{UO}_{2}{ }^{2+}$ & 28 & 0.95 & 11
\end{tabular}

aLeach values for the hydrophobic clays are corrected for the mass of organic material contained within the added monolayer. They represent leachability per gram of original unmodified clay.

This change in the local coordination affects the ability of the clay-monolayer system to retain the interlayer ion. The results of leach tests from ion-exchanged clays before and after surface modification are shown in Table 1. For the four cations examined, the hydrophobic clay created using OTMS is approximately 20 times more effective than the unmodified bentonite in retaining the interior ion. In the case of the uranyl cations, the clay modified with OTCS is an order of magnitude worse than the $\mathrm{UO}_{2}{ }^{2+}$-bentonite treated with OTMS in keeping the cation within the aluminosilicate matrix. We believe that this behavior is a direct result of the complexation of chloride anions with the stored cation. The reaction of an alkyltrichlorosilane, $\mathrm{RSiCl}_{3}$, with the clay surface and the water adsorbed there, forms siloxane bonds, -Si-O-Si-, and hydrochloric acid, $\mathrm{HCl}$. In the case of divalent cations, the replacement of two or more neutral water molecules with negative 
chloride anions from the acid results in a complex that is no longer positively charged. These chlorinated species are easily leached from the mineral, since the coulombic forces which normally hold the cation in place are no longer effective. Therefore, both the coulombic and hydrophobic properties of the modified clays are necessary to encapsulate the interlayer cation within these systems.
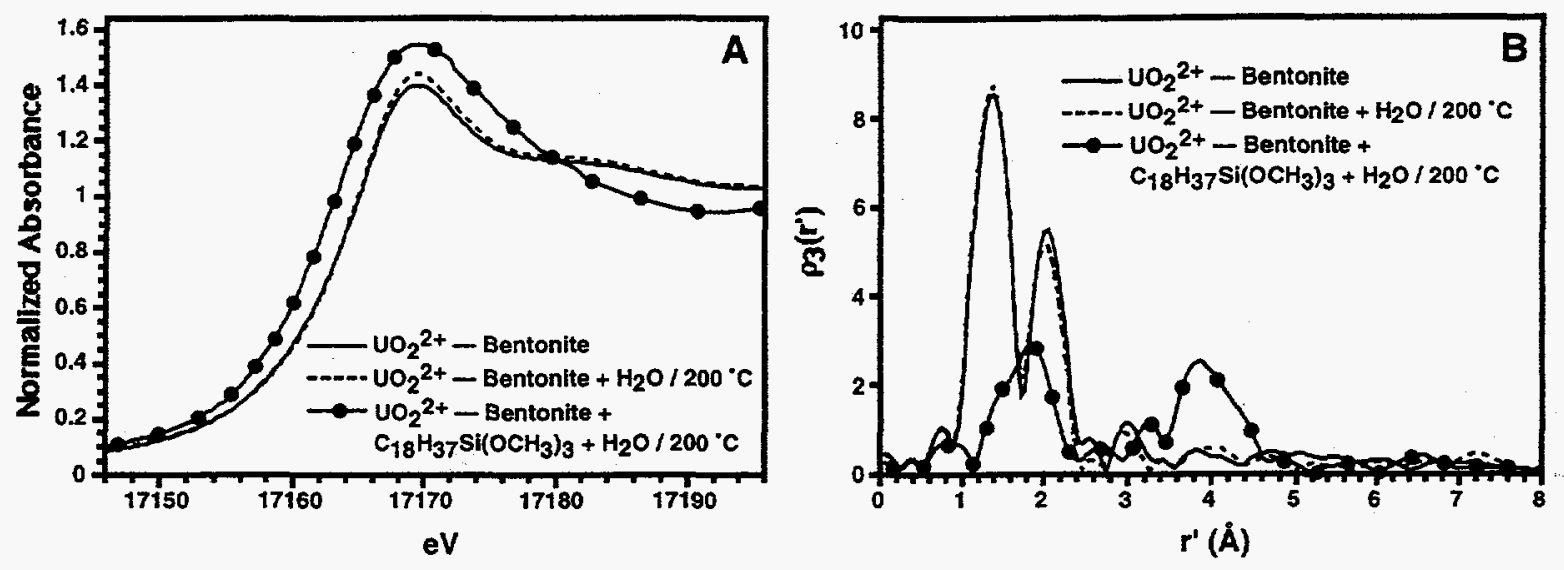

Figure 3. (A) X-ray absorption near edge spectra (XANES) and (B) radial structure functions (not phase corrected) for uranyl $\left(\mathrm{UO}_{2}{ }^{2+}\right.$ ) in the interlayer of bentonite: (1) ion-exchanged clay ( - ), (2) after hydrothermal processing at $200{ }^{\circ} \mathrm{C}(-\ldots)$, and (3) after hydrothermal processing of the modified uranyl clay created using octadecyltrimethoxysilane $\left(\mathrm{C}_{18} \mathrm{H}_{37} \mathrm{Si}\left(\mathrm{OCH}_{3}\right)_{3}\right.$, $\AA^{-1}$. $)$. The range for the forward Fourier transforms was $\Delta \mathrm{k}=1.0-11.0$

Hydrothermal and Thermal Processing. In order to simulate the effects of long term storage on these materials, as well as the effects of extreme conditions which may occur in a geologic repository, we have subjected both hydrophobic and hydrophilic clays that contain uranyl $\left(\mathrm{UO}_{2}{ }^{2+}\right)$ cations to hydrothermal processing. ${ }^{9}$ Figure 3 shows the near edge spectra and radial distributions for uranyl in bentonite before and after such treatment. Figure 3 also shows the XAS spectra from a uranyl-bentonite after both addition of an organic monolayer, formed from OTMS, and exposure to hydrothermal conditions. For the simple uranyl-bentonite, the XANES and radial structures are unchanged after hydrothermal processing. The two peaks in the radial distribution between $r^{\prime}=1$ and 2.5 $\AA$ reflect the presence of two axial oxygen atoms, which are directly bound to the uranium, and approximately 5 equatorial oxygen atoms from water molecules which are complexed to the uranyl species. 10 The spectra of a uranyl-clay after application of an organic monolayer but prior to hydrothermal treatment (not shown) are identical to those of the uranyl-bentonite. However, when the monolayer is present, exposure to hydrothermal conditions shifts the absorption edge approximately $3 \mathrm{eV}$ to lower energy. This shift is confirmed by a lowering of the energy parameter in the EXAFS fits by $3.5 \mathrm{eV}$. At the same time, the axial and equatorial features of uranyl have essentially disappeared from the 
radial structure function, to be replaced by a single peak centered at $r^{\prime}=1.8 \AA$. Simultaneously, a uranium-uranium correlation appears at $r^{\prime}=4 \AA$. These changes are consistent with the reduction of uranium to the +4 oxidation state, and the aggregation of the uranium into small, disordered $\mathrm{UO}_{2}$ particles. The unresolved shoulder in the radial distribution at $r^{\prime}=1.42 \AA$ may indicate the continued presence of a small amount of unmodified uranyl cations.
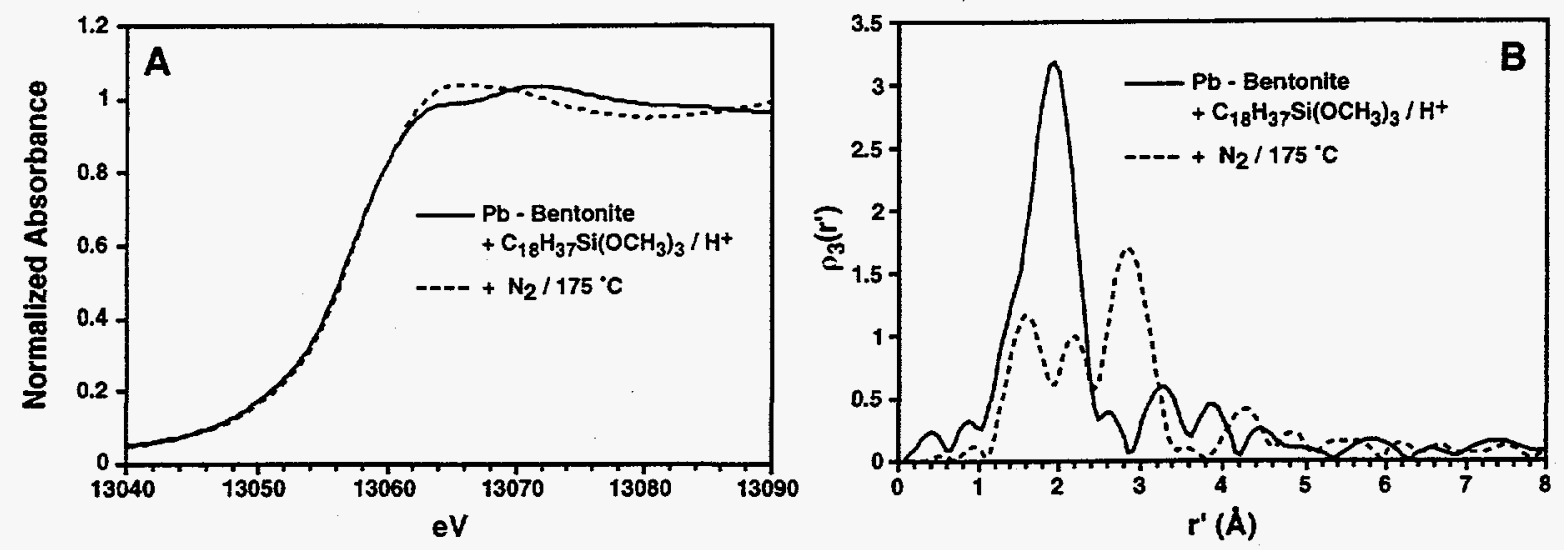

Figure 4. (A) X-ray absorption near edge spectra (XANES) and (B) radial structure functions (not phase corrected) for $\mathrm{Pb}$ in the interlayer of bentonite after modification with octadecyltrimethoxysilane $\left(\mathrm{C}_{18} \mathrm{H}_{37} \mathrm{Si}\left(\mathrm{OCH}_{3}\right)_{3}\right)$ : (1) hydrophobic clay ( - ) and (2) after heating to $175^{\circ} \mathrm{C}$ under nitrogen $(---)$. The range for the forward Fourier transforms was $\Delta \mathrm{k}=1.7-9.0$ $\AA^{-1}$.

We have performed related experiments with $\mathrm{Pb}$-bentonite. The hydrophobic clay that results from the addition of OTMS was heated to $175^{\circ} \mathrm{C}$ under nitrogen. The XAS spectra for this clay before and after heating are shown in Figure 4. There is no shift in the energy of the absorption edge, indicating that reduction of the lead has not occurred. However, the EXAFS data demonstrate that the lead ions, which are initially separate within the interlayer, coalesce into larger structures. This behavior is similar to that observed when an unmodified $\mathrm{Pb}$-bentonite is exposed to the same conditions. 11

The fact that uranyl is reduced while lead does not is apparently not due to differences between thermal and hydrothermal processing. Thermal treatment of $\mathrm{Cu}$ bentonite after application of OTMS also results in reduction and aggregation of the cupric ions (Figure 5). The product clay contains a mixture of species. Inspection of the second derivatives of the edge demonstrates that the $1 \mathrm{~s}-4 \mathrm{p}$ transitions of both $\mathrm{Cu}(\mathrm{II})$ and $\mathrm{Cu}(\mathrm{I})$ are present in the near edge spectrum. This fact is confirmed by the continued presence of the is-3d transition, although at a lower intensity than that in the original $\mathrm{Cu}$-bentonite. This transition does not appear for cuprous compounds since such species have a filled $3 \mathrm{~d}$ shell. 12 
The same changes in the XANES and EXAFS of $\mathrm{Cu}(\mathrm{II})$ occur when a hydrophilic $\mathrm{Cu}$-bentonite is heated to $180^{\circ} \mathrm{C}$ under hydrogen gas. The fact that heating in the presence of an organosilane monolayer or hydrogen results in the same species suggests that there is a reductive source that is the equivalent of hydrogen in the organic systems. This source is either the silane itself, methanol, which is a by-product of the polymerization of the silane on the surface, or residual amounts of the acid catalyst.
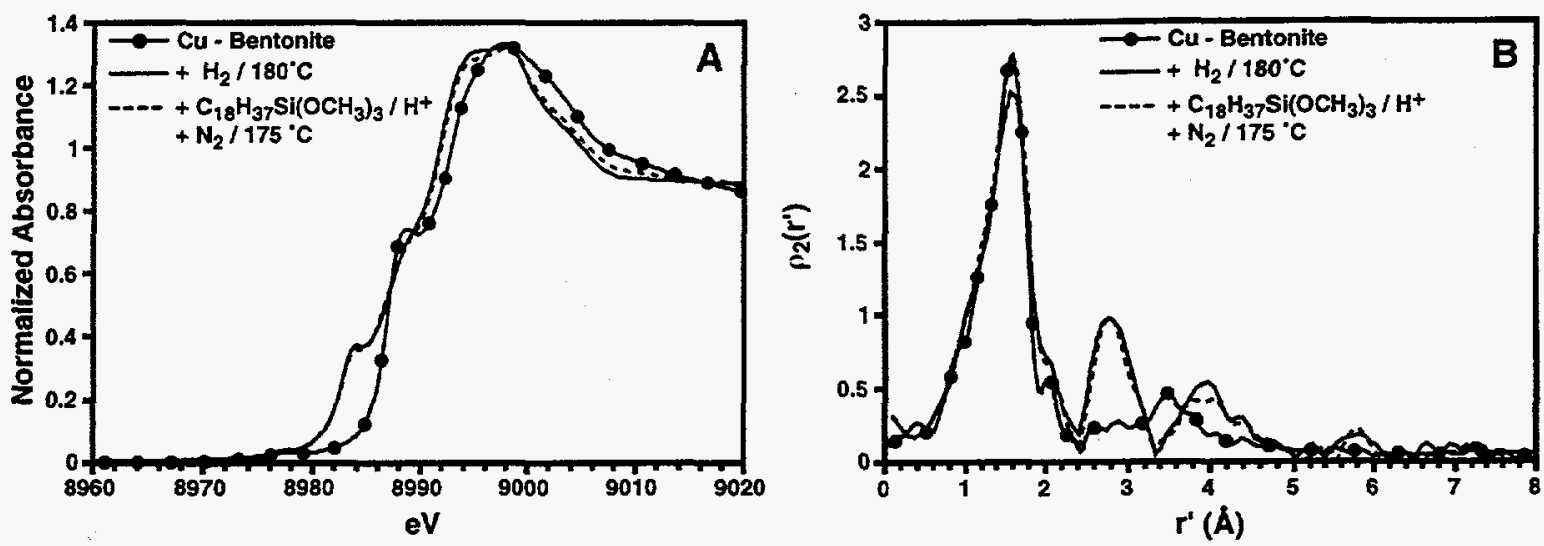

Figure 5. (A) X-ray absorption near edge spectra (XANES) and (B) radial structure functions (not phase corrected) for $\mathrm{Cu}(\mathrm{II})$ in the interlayer of bentonite: (1) ionexchanged clay (--), (2) after heating under hydrogen to $180^{\circ} \mathrm{C}$ ( _ - ) and (3) after thermal processing of the modified $\mathrm{Cu}$-clay created using octadecyltrimethoxysilane $\left(\mathrm{C}_{18} \mathrm{H}_{37} \mathrm{Si}\left(\mathrm{OCH}_{3}\right)_{3},---\right)$. The range for the forward Fourier transforms was $\Delta \mathrm{k}=1.8-13.0 \AA^{-1}$.

Each of the ions examined aggregates upon hydrothermal or thermal treatment in a surface modified clay. In addition to the ions discussed above, we have found that thorium conglomerates but is not reduced in the modified clays. Whether reduction occurs along with aggregation appears to be a function of the reduction potential of the stored ion. The reduction potentials for $\mathrm{Cu}^{2+}$ (to $\mathrm{Cu}^{+}$), $\mathrm{UO}_{2}{ }^{2+}$ ( to $\left.\mathrm{UO}_{2}\right), \mathrm{Pb}^{2+}($ to $\mathrm{Pb}(0))$, and $\mathrm{Th}^{4+}$ ( to $\mathrm{Th}(0)$ ) are $0.16,0.27,-0.13$, and $-1.83 \mathrm{~V}$ respectively. 13 We have only observed reduction for the former two species, for which reduction results in the formation of a more stable species.

\section{CONCLUSION}

These studies have demonstrated how surface modification affects the chemical and physical structure of ions held within the interlayers of clay minerals and the ability of such minerals to retain cations within their matrix. The addition of an organic film to clay minerals also perturbs the behavior of interlayer cations upon thermal and hydrothermal treatment. The latter results can serve as models for the interactions which occur in nature between ions, clay minerals, and organic compounds. 


\section{ACKNOWLEDGMENTS}

This research was supported by the Strategic Environmental Research and Development Program of the U. S. Department of Defense and the Division of Chemical Sciences, Office of Basic Energy Sciences, U. S. Department of Energy under contract W31-109-ENG-38.

\section{REFERENCES}

1. R. E. Grim, Clay Mineralogy, 2nd ed. (McGraw-Hill, New York, 1968).

2. Jule A. Rabo, Zeolite Chemistry and Catalysis (American Chemical Society, Washington, D. C., 1976).

3. G. W. Brindley and G. Brown, "Crystal Structures of Clay Minerals and Their X-ray Identification," (Mineralogical Society, London, 1980).

4. D. T. B. Tennakoon, J. M. Thomas, M. J. Tricker, and J. O. Williams, J. Chem. Soc. Dalton 1974, 2207-2211 (1974).

5. S. R. Wasserman, K. B. Anderson, K. Song, S. E. Yuchs and C. L. Marshall, U. S. Patent Applied For.

6. R. Maoz and J. Sagiv, J. Colloid Interface Sci. 100, 465-496 (1984).

7. S. R. Wasserman, Y.-T. Tao, and G. M. Whitesides, Langmuir 5, 1074-1087 (1989).

8. J. Mustre de leon, J. J. Rehr, S. I. Zabinsky, and R. C. Albers, Phys. Rev. B44, 4146-4156 (1991).

9. L. L. Hench, D. E. Clark, and E. L. Yen-Bower, Nucl. Chem. Waste Manag. 1, 59-75 (1980).

10. F. A. Cotton and G. Wilkinson, Advanced Inorganic Chemistry, 5th ed. (John Wiley and Sons, New York, 1988).

11. S. R. Wasserman (unpublished).

12. F. W. Lytle, R. B. Greegor, and A. J. Panson, Phys. Rev. B 37 (4), 1550-1562 (1988).

13. A. J. Bard, R. Parsons, and J. Joseph, "Standard Potentials in Aqueous Solutions," (Marcel Dekker, New York, 1985 ). 